\title{
Learning Style Preferences And Perceptions Of Undergraduate Nursing Students Upon Applying Web- Based Learning Modules.
}

\author{
Sahar Mohamed Soliman \\ Assist. Professor of Community Health Nursing, Faculty of Nursing, Mansoura University, Egypt
}

\begin{abstract}
:
Background: In the face of severe faculty shortages in constrained countries' resource-, electronic learning (elearning) was providing the chance for improving access to nursing education. Utilization of e-learning can result in greater educational opportunities for students, and enhancing faculty effectiveness and efficiency. Learning styles could be unique to every individual. Therefore, it is essential to expose learners to different methods of teaching and learning to promote the learning process. Web-based learning is a good method that encompasses a variety of educational approaches, such as simulation and basic problem solving combined with tutorial support. It also provides multiple self-assessment opportunities to allow students explore their level of understanding.

Objective: The study aimed to describe the undergraduate nursing students' learning style preferences and perceptions upon applying web based learning modules.

Study design: cross-sectional study was used.

Subjects and sampling: Undergraduate $4^{\text {th }}$ level who were registered at community health nursing in the second term during the academic year 2015-2016 by using convenient sampling technique.

Setting: The study took place at the Faculty of Nursing, Mansoura University.

Tools: the first tool was a self- administered demographic characteristics and learning style assessment was used. The learning style was assessed by adopting VARK questionnaire that was developed by Fleming (2008) to identify students learning style. The second tool was a scale developed to assess students' perception. This 4points likert scale starts with "strongly agree" to "strongly disagree", to obtain the undergraduate students' perception toward Web- based learning after applying the developed modules. The perception assessment included open ended questions to identify challenges that students have faced with web-based learning and any other negative feedback.

Results: The study revealed that $29.1 \%$ of students preferred aural learning style. The majority (81.8\%)of them strongly agreed that web based leaning offers the opportunities to self-learn and $85 \%$ recommended applying of web based learning in all courses.

Conclusion: The main conclusion drawn from the current study is that the majority of the undergraduate students strongly agreed on the combination of traditional learning methods and Web based learning. They strongly agreed that Web based learning modules covered students learning style preferences. The majority of students preferred the mixed learning style.
\end{abstract}

Key Words: Web-based learning - Community health nursing -Learning style preferences- Undergraduates students' perception

\section{Introduction}

Nursing field has been described as a complex, dynamic and highly technical field. There is an urgent need to redesign nursing education to prepare nursing students for technological demands of the global nursing world for the twenty first century ${ }^{(\mathbf{1})}$. The Egyptian Ministry of Education and Higher Education emphasized using technology in teaching, designing online courses, and training staff on content development, and management of electronic learning (e-learning) ${ }^{(2)}$.

Web learning has become commonly used in teaching in most of higher education institutions. The popularity of web learning is mainly due to the concept of "anywhere" and "anytime". Using of multimedia attracts teachers and learners to e- learning ${ }^{(3,4)}$, which strongly encourages the use of multimedia as an effective teaching - learning tool. Theories of learning style are the effective ways for helping teachers to recognize the students' needs ${ }^{(5)}$. Personal awareness of learning styles is the first step to achieve an optimal learning environment. Student's learning style preference has an effect on teaching approaches, which close the gap between learning and delivery instructions. Therefore, it is preferable to understand students' learning styles and preferences when designing online courses ${ }^{(6)}$. Moreover, recognizing students' learning styles and preference enables educational institutions to design learning approaches that match students' styles. The evidence suggests that through improving students' awareness about their own learning style, they become able to take responsibility for their own learning, which leads to positive learning outcomes ${ }^{(7,8)}$. Fleming $(2008)^{(9)}$, 
suggested four classifications that indicate the sensory modalities used to present information, as an acronym "VARK". This acronym represent the for learning styles "Visual (V), Auditory (A), read/write (R), and Kinesthetic (K)". The VARK focused on the means by which people like information to be delivered to them and the means by which they liked to deliver their communication. ' $\mathrm{V}$ ' denotes Visual: learners prefer drawing a diagram or picture. 'A' denotes Aural: learners prefer to listen rather than take notes. ' $R$ ' denotes Read/Write: learners prefer printed words and text. ' $\mathrm{K}$ ' denotes Kinesthetic: learners use live experience and practice in order to learn. Therefore, the aim of this study is to identify learning style preferences and perceptions of undergraduate nursing students upon applying web based learning modules.

\section{Aim Of The Study}

The study aimed to describe the undergraduate nurses' students' learning style preferences and perceptions upon applying web based learning modules.

\section{Subjects And Methods}

3.1. Study design: cross-sectional study design was used to describe students learning style preferences and their perception upon applying web based learning modules.

\subsection{Research questions:}

1-What are the learning styles of undergraduate students who registered at the level 4 who are studying "Community health nursing course?

2- What is the students' perception upon applying web- based learning modules?

\subsection{Study Setting:}

The study was conducted at Faculty of Nursing Mansoura University.

\subsection{Subjects and Sampling:}

Convenient sampling technique was used to recruit subjects who involved in the study. All nursing students $(n=275)$ were registered at the level 4 and studied "Community health nursing course" in the second term of the academic year 2015- 2016

\subsection{Tools of the study:}

Tool I: Self- administered Demographic characteristics and learning style assessment This tool included two parts:

Part 1: This part assesses the students' demographic characteristics, age and gender.

Part 2: It included VARK Questionnaire (Version 7.1), that was developed by Fleming (2008) [9]. It was used to determine the preferred learning style of students. It consists of 16 statements that provide a profile of an individual's preferences for how information is received and processed. Each statement has four choices that describe a situation and allows the responder to choose one or more response that they would take. Each action corresponds to one of the four VARK learning dimensions, which are "V" visual, "A" aural, "R" reading/writing, and " $\mathrm{K}$ " kinesthetic.

\section{Tool II- Self-administered Students' perception questionnaire:}

This questionnaire was developed by the researchers to obtain the undergraduate students' perception toward Web- based learning after applying the developed modules. The perception scale is a 4-points likert scale that starts with "strongly agree" to "strongly disagree". This scale included two parts namely; skills that are acquired by the WBL and the available facility and resources that serve this educational approach. The questionnaire included open-ended questions that explored the challenges and the negative feedbacks which the students have faced with web- based learning.

\subsection{Methods:}

\section{1- Ethical consideration:}

The Community Health Nursing Department Committee approved to introduce Web based modules on diabetes mellitus and Home visiting as an educational approach in the course of "community health nursing".

2-Approval was obtained from the Research Ethics Committee, Faculty of Nursing-Mansoura University.

3- Undergraduate students were informed about the study at the beginning of the course. They were ensured that their participation and their opinions about the course would have no effect on their academic evaluation. Researcher assured that all questionnaires were anonymous and considered as confidential data.

\section{Tools development:}

After reviewing of national and international literatures, this review was a guide for developing two tools; first tool was self- administered questionnaire demographic characteristics and learning style assessment to assess students demographic characteristics and adapting VARK questionnaire that was developed by 
Fleming (2008) to identify students learning style. The second tool was a self- administered questionnaire to assess students' perception on a 4- points likert scale toward Web- based learning after applying the developed modules. The scale starts with "strongly agree" to "strongly disagree". Open ended questions were included to, identify challenges and the negative feedbacks that students have faced with web- based learning.

\section{Validity and reliability of tools}

A pilot study conducted on a group of 28 internship students who were registered at $4^{\text {th }}$ year in the previous academic year and had previous experience with WBL to test the content validity of the study tools. Based on the finding of the pilot study, modifications were made to the tools. The reliability was tested by statistical SPSS package to yield a Cronbach's alpha of 0.94 .

\section{Application of diabetes mellitus and home visiting modules as WBL modules:}

The diabetes mellitus and home visiting modules were among community health nursing course modules that equip nursing students with different practical skills. According to the objectives and intended learning outcomes of these modules, the content and multimedia were designed and uploaded to a website. The designing of the website was achieved in collaboration with a web designer.

The main simulated procedures in diabetes mellitus module, were blood glucose test and insulin injection that was illustrated in demonstration videos. The home visit process and bag technique were illustrated in demonstration videos for home visiting module. Written text with pictures and animated graphics were also used to produce the two modules. An interactive program in form of virtual lab was used for re-demonstration of blood glucose testing and insulin injection and bag technique procedures. In addition to practical skills of the two web- based modules concerned also with providing knowledge base related to each topic. The web-based modules also contained a chat room for posting questions and discussion between students-students and students- teacher group. The web- based modules included structured self-evaluation test in the form of multiple-choice questions.

\section{Data collection:}

At the beginning of the semester, each student was asked to determine his/ her learning style by using the first tool. At the beginning of each rotation, "home visiting or diabetes mellitus clinic", the rotation objectives and the purpose of using web- based learning were explained. Then the website "www.healthgarden.com" was distributed to students and they asked to access it for studying the assigned module. By the end of the two rotations, students were asked to provide their perception about Web- based learning and their feedback about this experience by using the second tool.

\section{Data analysis:}

The data was sorted, coded, and analyzed by using SPSS (Stand for statistical product and service solution), version 16. Descriptive data analysis was performed to achieve the study aim.

\section{Results}

Table (1) shows the demographic characteristics of the studied students. The age of $73.1 \%$ of the students ranged from 20 to 22 years, and $69.5 \%$ of students were female. Concerning students learning style preferences, it was found that $22.5 \%$ of students prefer visual while $29.1 \%$ of them preferred aural learning style. Slightly more than one quarter $(26.5 \%)$ of them preferred read and write learning style. More than half $(53.8 \%)$ of students preferred multiple learning styles.

Table (2) illustrates students perception toward their experience of web-based learning modules, $80 \%$, of students strongly agreed that Web based learning improve their skills of using information and communication technology. In addition, $85 \%$ of them strongly agreed that Web based learning helps the interaction among students with each other and with their teachers as well. While $81.8 \%$ of them strongly agreed that WBL offers the opportunity to self-learning. Concerning allocated facilities and resources for WBL, $81.8 \%$ of students strongly agreed that WBL safe time and effort and strongly agreed that it is easy to access the information regardless of time and place. Table (3) shows students' perception regarding used media in relation to their learning styles requirement. Concerning visual learning style $90 \%$ of students agreed that videos demonstrations was clear with proper font and $94.5 \%$ of them agreed that there were different and attractive colors. Regarding to aural learning style, $90 \%$ of students agreed that the auditory presentation of information can grasp students' attention and $97.5 \%$ agreed there was feedback for students and illustration of contents re- demonstration. As regards to reading and writing learning style, $90 \%$ of students agreed that the information was organized. While $97.5 \%$ of students agreed that, there was trial and error method and $94.5 \%$ agreed that the activities provided were effective for kinesthetic learning styles. 
Table (4) shows the distribution of student preferences toward using of Web based learning, $22.5 \%$ of students agreed that learning with traditional methods is the preferred method, $77.5 \%$ of them agreed that Web based methods were their preferable learning method. While $90 \%$ agreed that the combination between traditional method and Web based method are the preferred. The majority of students $88.7 \%$, and $85 \%$ recommended using of web based leaning for their colleagues and applying of web based learning in all courses; respectively.

Table (5) illustrates the challenges facing students with web- based learning. The majority $85.5 \%$ of students revealed that Web based learning needs teachers with special characters. However, $73.8 \%$ of students mentioned that Web based learning focused on the skills without paying attention to their emotional condition. While $70.9 \%$ of them revealed that WBL is costly, as less than third $22.5 \%$ of them reported unavailability of internet connections and $7.3 \%$ revealed ergonomic problems due to uses of web based learning. On the other hand, only $5.8 \%$ of students reported unavailability of computers at their homes.

Table 1: Distribution of fourth level students according to their demographic characteristics and learning style preferences

\begin{tabular}{|l|l|l|}
\hline Demographic characteristics & $\mathbf{n = 2 7 5}$ & \% \\
\hline Age & & \\
\hline $20-22$ years & 201 & 73.1 \\
\hline More than 22 & 74 & 26.9 \\
\hline Gender & & \\
\hline Male & 84 & 30.5 \\
\hline Female & 191 & 69.5 \\
\hline Most preferable learning VARK style & & \\
\hline "V" visual & 62 & 22.5 \\
\hline "A" aural & 80 & 29.1 \\
\hline "R" reading/writing & 73 & 26.5 \\
\hline "K" kinesthetic & 60 & 21.8 \\
\hline Multiple VARK learning style & & \\
\hline One style & 127 & 46.2 \\
\hline More than two styles & 148 & 53.8 \\
\hline
\end{tabular}

Table 2: Distribution of fourth level students' perception toward web based learning upon applying the modules

\begin{tabular}{|c|c|c|c|c|c|c|c|c|}
\hline \multirow{2}{*}{ Web based learning } & \multicolumn{2}{|c|}{ Strongly agree } & \multicolumn{2}{|c|}{ Agree } & \multicolumn{2}{|c|}{ Disagree } & \multicolumn{2}{|c|}{ Strongly disagree } \\
\hline & $\mathbf{N}$ & $\%$ & $\mathbf{N}$ & $\%$ & $\mathbf{N}$ & $\%$ & $\mathbf{N}$ & $\%$ \\
\hline \multicolumn{9}{|l|}{ Acquired skills } \\
\hline $\begin{array}{l}\text { Improve using of information and communication } \\
\text { technology skills of the student }\end{array}$ & 220 & 80 & 50 & 16.2 & 20 & 7.3 & 5 & 1.8 \\
\hline $\begin{array}{l}\text { Allow the exchange of knowledge and experiences among } \\
\text { students each other and with their teachers }\end{array}$ & 235 & 85 & 30 & 10.9 & 10 & 3.6 & 5 & 1.8 \\
\hline $\begin{array}{l}\text { Help students to create a new collective thinking, problem } \\
\text { solving and collaborative leaning environments }\end{array}$ & 240 & 87.3 & 30 & 10.9 & 5 & 1.8 & 5 & 1.8 \\
\hline $\begin{array}{l}\text { Helps the interaction between students and each other and } \\
\text { with their teachers on the other hand }\end{array}$ & 235 & 85 & 30 & 10.9 & 10 & 3.6 & 5 & 1.8 \\
\hline Offers the opportunity to self- learn & 225 & 81.8 & 35 & 12.7 & 9 & 3.2 & 6 & 2.2 \\
\hline \multicolumn{9}{|l|}{ Students apply learnt information rather than memorize } \\
\hline \multicolumn{9}{|l|}{ Facilities and resources } \\
\hline Safe time and effort & 225 & 81.8 & 5 & 1.8 & 25 & 9 & 20 & 7.3 \\
\hline Ease to access the information regardless of time and place & 225 & 81.8 & 5 & 1.8 & 25 & 9 & 20 & 7.3 \\
\hline Facilitate the search for information needed by the students & 235 & 85 & 30 & 10.9 & 10 & 3.6 & 5 & 1.8 \\
\hline $\begin{array}{l}\text { Facilitate curriculum updating on the internet at a lower } \\
\text { cost compared with other teaching methods }\end{array}$ & 230 & 83.6 & 20 & 7.3 & 10 & 3.6 & 10 & 3.6 \\
\hline
\end{tabular}


Learning Style Preferences And Perceptions Of Undergraduate Nursing Students Upon Applyi...

Table 3:Distribution of the fourth level student s' perceptions regarding materials

\begin{tabular}{|c|c|c|c|c|c|c|}
\hline VARK Items & \multicolumn{2}{|c|}{ Agree } & \multicolumn{2}{|c|}{ Neutral } & \multicolumn{2}{|c|}{ Disagree } \\
\hline Videos demonstrations are clear & 250 & 90 & 20 & 7.3 & 5 & 1.8 \\
\hline Pages are arranged & 265 & 96.4 & 8 & 2.9 & 2 & 0.7 \\
\hline Graphics are clear & 250 & 90 & 10 & 3.6 & 15 & 5.5 \\
\hline Simulation permit learners to review and see example & 235 & 85 & 20 & 7.3 & 20 & 7.3 \\
\hline $\begin{array}{l}\text { Auditory presentation of information can grasp } \\
\text { students attention }\end{array}$ & 250 & 90 & 15 & 5.5 & 10 & 3.6 \\
\hline Give enough verbal instructions & 230 & 83 & 35 & 12.7 & 10 & 3.6 \\
\hline Explain of ideas & 235 & 85 & 20 & 7.3 & 20 & 7.3 \\
\hline Encourage learner participation & 240 & 87.3 & 30 & 10.9 & 5 & 1.8 \\
\hline Give the learner feedback & 267 & 97.5 & 6 & 2.2 & 2 & 0.7 \\
\hline Vocabulary is relevant to learner ability & 253 & 92 & 20 & 7.3 & 3 & 1.1 \\
\hline Information is sufficient in scope and depth & 244 & 88.7 & 25 & 9 & 7 & 2.5 \\
\hline Logical progression of topics & 244 & 88.7 & 25 & 9 & 6 & 2.2 \\
\hline Clear and understandable content & 250 & 90 & 20 & 7.3 & 5 & 3.6 \\
\hline Give enough explanation & 246 & 89.5 & 20 & 7.3 & 9 & 3.3 \\
\hline \multicolumn{7}{|l|}{ kinesthetic } \\
\hline Use trial and error method is beneficial & 267 & 97.5 & 6 & 2.2 & 2 & 0.7 \\
\hline The activities provided are effective & 260 & 94.5 & 10 & 3.6 & 5 & 1.8 \\
\hline
\end{tabular}

Table 4: Distribution of fourth level student's preferences regarding Web based learning

\begin{tabular}{|l|l|l|l|l|l|l|}
\hline \multirow{2}{*}{ Items } & \multicolumn{2}{|l}{ Agree } & \multicolumn{2}{l}{ Neutral } & \multicolumn{2}{l}{ Disagree } \\
\cline { 2 - 7 } & $\mathbf{N}$ & $\%$ & $\mathbf{N}$ & $\%$ & N \\
\hline Prefer to learn with traditional methods & 62 & 22.5 & 200 & 72.7 & 13 & 4.7 \\
\hline Prefer to learn with Web based methods & 213 & 77.5 & 32 & 11.6 & 30 & 10.9 \\
\hline $\begin{array}{l}\text { Prefer to learn by combination with Web based and } \\
\text { traditional methods }\end{array}$ & 250 & 90 & 5 & 1.8 & 20 & 7.3 \\
\hline $\begin{array}{l}\text { Recommend using web based leaning for other } \\
\text { colleagues }\end{array}$ & 244 & 88.7 & 25 & 9 & 7 & 2.5 \\
\hline $\begin{array}{l}\text { Recommend applying of web based learning in all } \\
\text { courses }\end{array}$ & 235 & 85 & 20 & 7.3 & 20 & 7.3 \\
\hline
\end{tabular}

Table 5: Challenges facing fourth level students with web based learning

\begin{tabular}{|l|l|l|}
\hline Item & $\mathbf{N}=\mathbf{2 7 5}$ & $\mathbf{\%}$ \\
\hline $\begin{array}{l}\text { Web based learning focused on the skills without paying attention to the } \\
\text { emotional condition of the student }\end{array}$ & 203 & 73.8 \\
\hline Web based learning needs a special quality of teachers & 235 & 85.5 \\
\hline Web based learning needs a high financial cost & 195 & 70.9 \\
\hline Unavailability of internet connections & 62 & 22.5 \\
\hline Web based learning needs more time & 49 & 17.8 \\
\hline Difficult of searching & 36 & 13.1 \\
\hline Web based learning needs computer skills & 33 & 12.0 \\
\hline No interaction between colleagues & 25 & 9.1 \\
\hline Absence of tutor role & 21 & 7.6 \\
\hline Ergonomic problems & 20 & 7.3 \\
\hline Needs a special quality of teachers & 17 & 6.2 \\
\hline Unavailability of computers at home & 16 & 5.8 \\
\hline
\end{tabular}

\section{Discussion}

Nowadays education is changing at a rapid pace; uses of technology become more sophisticated and more widespread (10). Advanced technology has made the creation of web-based courses possible. The increasing in band width and download speeds, new technologies for compressing files and steaming media served make it possible to routinely use multimedia, including video in the design of web based education ${ }^{(10)}$.

However, traditional methods are still the most common teaching methods used in nursing. Educators are facing some challenges, such large number of students, difficulties in holding student attention and information recall ${ }^{(\mathbf{1 1}, \mathbf{1 2})}$. These issues have compelled nurse educators to change and adopt alternative methods like web based learning. This method enables students to get information, interact with other colleagues and improve learning within a virtual environment at any time and at any place ${ }^{(13)}$. Web based activities tailored 
with multiple learning styles are one of the effective way that help teachers to recognize students' needs. The current study revealed that, nursing students have multiple learning styles and the different learning styles were equally distributed among studied students. However, the Aural style was the most preferred learning style among $29.1 \%$ of students. The same result was stated by researchers ${ }^{(\mathbf{1 4})}$, who reported that more than one- third of faculty and technical nursing students in Alexandria University preferred aural learning style.

Most of students in the current study strongly agreed that Web based learning improved their using of information and communication technology skills. More than three quarters of them strongly agreed that WBL offers the opportunity to self- learning, safe time, effort and it is easy to access the information regardless of time and place.

Concerning visual learning style, the majority of students agreed that video demonstration was clear with proper font and different attractive colors. Regarding to aural style, the majority of students agreed that the presentation of information could grasp students' attention and give feedback. As regards to reading and writing style, the majority of students agreed that the information was organized, up to date, and included trial and error method. Activities provided were more effective for kinesthetic learning styles. It seems that web-based learning fulfills students' needs as more than half of them preferred multiple learning styles and more than two thirds of them preferred web based leaning. This finding was found on nursing students in Saint Mary University ${ }^{(15)}$. In addition, more than two thirds of students preferred web based leaning. This finding was the outcome of studies conducted on pharmacy students in Chicago state-USA ${ }^{(16)}$, on secondary school students in Canada ${ }^{(17)}$ and Students in Northern Kentucky University -US ${ }^{(18)}$ which revealed that the majority of their nursing students preferred web based as stated in the current findings. Nursing students of the current study recommended using of web based leaning method for their colleagues and to apply it in all courses. This result is enrolled with the author result ${ }^{(\mathbf{1 9})}$ who found that the web based learning provided Malaysian students with more knowledge and the graphics clarify the content meaning. Using of multimedia made learning a fun and students would be able to learn at their own time. Moreover, other studies in Thailand and University of Maryland-USA ${ }^{(20,21)}$, reported that web-based learning unit is useful and facilitate students learning process. It enabled them to grasp the main concepts of a topic. Animated graphics and colored pictures combined with voice attract the students' attention. Furthermore, students liked the web-based course much more than textbooks. Some students suggested replacing the traditional teaching with WBL in the near future. The same results were in consistence with study conducted in China, which illustrated that the Chinese nursing students believed that the online course could allow them to learn without restriction to time and space. Chinese students mentioned that online courses allowed them to visualize the actual communication in their future workplace and interactive teaching strategies stimulated their learning ${ }^{(22)}$. In addition, study conducted in Malaysia (19) revealed that less than half of Malaysian students did not prefer face to face method in comparing to online learning. Moreover, many authors ${ }^{(14,19,20)}$ concluded that innovative e- learning improve students level of understanding compared to the students who exposed to traditional educational method. In addition, those students showed high level of satisfaction toward e-learning].

In spite of these positive perceptions toward WBL, less than one third of students in the current study prefer to learn with traditional methods. This findings enrolled with researchers ${ }^{(23,24)}$ who stated that most students still prefer face to face interaction with the instructor because students perceive more individual attention from instructors in the classroom. In addition, students mentioned some challenges they have faced with web based learning. More than two thirds of them revealed that Web based learning focused on the skills without paying attention to the emotional status of students and web based learning was costly. Also less than one quarter reported unavailability of internet connection, while around ten percent of them reported that they missed interaction with their colleagues. The same result was mentioned in a study that reveled negative feedback of students toward online courses. It also reported difficulty in accessing online course and $10 \%$ of their respondents expressed that regular interaction with classmates in an online course was very important issue ${ }^{(18)}$.

\section{Conclusion}

Undergraduate nursing students accepted WBL as educational strategy. They strongly agreed that Web based learning improves skills of using information and communication technology and develops self- learning skills. The majority of students recommended using of web based leaning for their colleagues and applying of web based learning in all courses. WBL safes time and effort also its modules covered students learning style preferences. The majority of students preferred the mixed learning style.

\section{Recommendations}

This study recommended that teaching strategies would be based on students learning styles. WBL strategy be applied in all community health-nursing modules. 


\section{References}

[1]. Warren J.,ConnorsJ. Health information technology can and will transform nursing education. Nursing outlook, 2007; 55(1): 58-60

[2]. BillingsD., Halstead J . Teaching in nursing: A Guide for faculty, $4^{\text {th }}$ ed., Elsevier, United States of America.2012; 352-354, 359360

[3]. Paraia M., Shenoya P. ,Lohb K.Y. Students' perception of technology-assisted learning in undergraduate medical education - A survey. The Social Science Journal. 2015; 52: 78-82 Taylor's University College, Malaysia

[4]. Moyer BA., Wittmann-Price Ra. Nursing education: Foundation for excellence. $1^{\text {st }}$ ed. Chapter 10, Philadelphia, Davies Com. $2008 ; 184-203$

[5]. Williamson M., Watson R . Learning styles research: Understanding how teaching should be impacted by the way learners learn: Part III: Understanding how learners' personality styles impact learning. Christian Education

[6]. Journal. 2007; 4(1). 62-77. Available at: http://journals.biola.edu/cej/volumes/4/issues/1/articles/62, accessed 12 January 2015

[7]. Vorhaus J. Learning styles in vocational education and training. In: Penelope, P., Eva, B., \& Barry, M. (Eds.). International Encyclopedia of Education. Oxford: Elsevier, pp. 2010;376-382.

[8]. Fritz M.'Using learning styles inventories to promote active learning’. Journal of College Reading and Learning, 2002; 32(2): 183-9

[9]. Merriam SB., Caffarella RS., Baumgartner LM .Learning in adulthood: A comprehensive guide (3rd). Chapter 2, San Francisco: Jossey-Bass. 2007: 105-1599. Fleming N., (2008). VARK: A guide to learning styles. (Version7.1). Available at: http://www.varklearn.com/nglish/index.asp, accessed 4 January 2015

[10]. Hall DL., Drab SR., Campbell RK., Meyer., SM., Smith RB. Instructional design and assessment A Web-based inter-professional. Diabetes Education Course. American Journal of Pharmaceutical Education. 2007; 71(5) 93:1-8.

[11]. Dennison HA. Creating a computer-assisted learning module for the non-expert nephrology nurse. Nephrology nursing Journal. Journal of the American Nephrology Nurses' Association.2011;38(1): 41-52

[12]. Smaldino ES., Loether LD., Russell DJ. International technology and media for learning, person education, USA, 2012; 9(1): 123133

[13]. AllyM. Foundations of educational theory for online learning. In Anderson T, ElloumiF. Theory and practice of online Learning. 2nd ed. Canada. Athabasca University press. 2008; 15-44

[14]. Mohamed A., Anas Elwogoud H. Learning Styles of Community Health Nursing Students' at Faculty of Nursing and Technical Institute of Nursing - In Alexandria New York Science Journal, 2011;4(9)15. Brenda M.Nursing Student Preferred Learning Styles AND NCLEX .DOCTOR OF EDUCATION with an emphasis in Health Professions Education . Saint Mary faculty USA 2015

[15]. Jennifer A., Pharm D..Replacing traditional live lectures with online learning modules: Effects on learning and student perceptions. Teaching and Learning Chicago Currents in Pharmacy. Research BCPS Midwestern University 2015; 7 : 738- 744,

[16]. Michael K. Barbour. Secondary Students' Perceptions of Web-Based Learning. The Quarterly Review of Distance Education.2008;9(4): 357-371

[17]. John A. Huss., Shannon2013. The Perceptions of Students toward Online Learning at a Midwestern University: What are Students Telling Us and What Are We Doing About It? Inquiry in education. Northern Kentucky University 2013; 2(4) Article 5

[18]. Mai Neo.,Tse-Kian.,Neo,Wei-Li Yap.Students' perceptions of interactive multimedia mediated web-based learning: A Malaysian perspective Proceedings ascilite Melbourne 2008

[19]. Sailom G ab., TassaneePruksacheva b., BhinyoPanijpan a., PintipRuenwongsa. Development of a web-based learning medium on mechanism of labour for nursing students. Nurse Education Today. 2010; $30: 464-469$

[20]. Alex Koohang., Nicole A. Buzzetto-More. Student Perceptionsof Various E-Learning Components. University of Maryland Eastern Shore, Princess Anne, USA. Interdisciplinary Journal of E-Learning and Learning Objects 2008 (4).

[21]. An so n C.Y ., Tan g a., Nick Wong b., Thomas K.S., Wong c.Learning experience of Chinese nursing students in an online clinicalEnglish course: Qualitative study .Nurse Education Today2015; 35:61-66

[22]. Abdelaziz M kamel, Karam O, Abdelrahman. Evaluation of Elearning program versus traditional lecture instruction for undergraduate nursing students in a faculty of nursing. Teaching and Learning in nursing. 2011; 6 (2): 50-58

[23]. Valenta A, Therriault D, DieterN, Mrtek R. Identifying students attitudes and learning styles in distance education. Journal of Asynchronous learning networks, 2001; 5 (2) :1-15 